\title{
Los équidos en Isidoro de Sevilla (Orig. XII 1.38-61): fuentes, método, contenido y estructura del pasaje*
}

\author{
Joaquín Pascual Barea \\ Universidad de Cádiz \\ joaquin.pascual@uca.es \\ ORCID iD: http://orcid.org/0000-0001-9981-0780 \\ Equidae in Isidore of Seville (Orig. XII 1.38-61): \\ the passage's sources, method, content and structure
}

\begin{abstract}
Análisis e interpretación del pasaje de las Etimologías y de los términos tratados, incluyendo la corrección de lecturas, y el texto revisado. Señalamos sus fuentes, y explicamos la metodología y la concepción lingüística del autor respecto a la etimología y el significado de las palabras. Según la estructura subyacente y armazón científico en que se sustenta el texto, Isidoro distingue los asnos y caballos salvajes (onagri y equiferi) de los domésticos (asini y equi). Divide los asnos en burros de menor tamaño para trabajar (aselli), y en asnos grandes (asini Arcadici), y los caballos en una clase vulgar para el tiro de carros (ueredus), que incluye una variedad de menor tamaño (mannus), y otra clase de caballos nobles de silla, de la que menciona ocho razas según su origen geográfico. De los híbridos menciona el mulo (mulus), el burdégano (burdo) y el cruce de onagro y asna.
\end{abstract}

Palabras clave: caballo; asno; poni; onagro; salvaje; mulo; burdégano; garañón.
Analysis and interpretation of the passage of the Etymologies and of the treated words, including the correction of a few readings, and the revised text. We note its literary sources, and explain the author's methodology and linguistic conception regarding the etymology and meaning of words. According to the underlying structure and scientific frame in which the text is supported, Isidore distinguishes wild asses and wild horses (onagri and equiferi) from the domestic ones (asini and equi). He divides asses into smaller working donkeys (aselli) and big asses (asini Arcadici), and horses into a vulgar class for pulling carts (ueredus), including a variety of minor size (mannus), and another class of noble saddle-horses, of which he mentions eight races according to their geographical origin. Among the crossbreeds he mentions the mule (mulus), the hinny (burdo) and the cross of a wild ass and a jenny.

Key words: horse; donkey; poney; onager; wild; mule; hinny; stallion.

Cómo citar este artículo / Citation: Pascual Barea, Joaquín 2017: «Los équidos en Isidoro de Sevilla (Orig. XII 1.38-61): fuentes, método, contenido y estructura del pasaje», Emerita 85 (1), pp. 117-140.

* Este artículo forma parte del proyecto POII-2014-019-P, subvencionado por la Comunidad de Castilla-La Mancha.

Copyright: (C) 2017 CSIC. Este es un artículo de acceso abierto distribuido bajo los términos de la licencia de uso y distribución Creative Commons Attribution (CC-by) España 3.0. 


\section{INTRODUCCIÓN}

Me propongo explicar el pasaje sobre los équidos en su conjunto, y algunos de sus términos más controvertidos, a partir del análisis de su estructura y contenido en el contexto de la tradición literaria sobre el tema, y teniendo en cuenta las innnovaciones derivadas de la adaptación de las fuentes a la situación histórica y lingüística de la España visigoda, y al planteamiento y propósito de la obra. Pues el autor alteró el orden lógico de algunos términos debido en parte a su empeño por ofrecer el origen de los nombres más que su verdadera forma y significado, y por hacerlo solo en el lugar que creía oportuno, así como por la falta de tiempo y de fuerzas para revisar la obra, como refiere a Braulio de Zaragoza $^{1}$.

\section{FuENTES PRINCIPALES DEL PASAJE}

Consciente del valor e importancia de su labor, Isidoro recopiló ${ }^{2}$ y seleccionó los datos esenciales sobre los équidos y sobre el origen y significado de la terminología relativa a ellos a partir de una docena de obras escritas desde la Antigüedad hasta su tiempo, de las que son las más recientes las que usa de forma directa. En este pasaje ${ }^{3}$ no cita ninguna de sus fuentes, aunque transcribe de forma casi literal frases de obras de Paladio, Solino, Jerónimo y Vegecio, y toma definiciones y explicaciones de los comentarios y textos gramaticales de Servio y Festo 4 .

El tratado de agricultura de Paladio (IV 14.3-4; 13.2-4; 13.7) le proporciona parte del esquema general y noticias sobre las cualidades del asno (40) y sobre las características que deben reunir los buenos caballos en hechura y belleza, en conducta y en colores (45-48). A la lista de quince nombres de capas (48), procedente de la más numerosa de Paladio con ligeras alteracio-

1 Cf. Díaz y Díaz 1982, pp. 164-170.

${ }^{2}$ Cf. Fontaine 2000, pp. 329-344, sobre la defensa que hace Isidoro de Virgilio como compilador de versos ajenos (Orig. X 44).

${ }^{3}$ Los números 38 al 61 entre paréntesis indican los parágrafos o lemas del pasaje, que edito en apéndice.

${ }^{4}$ Cf. Díaz y Díaz 1982, pp. 180-199 sobre el método y fuentes de la obra. Grial 1999, pp. 225-226 y Arévalo 1801, pp. 45-50 traen las principales fuentes. André 1986, pp. 12-22 las trata en la introducción y en las notas. 
$n^{5}{ }^{5}$, añade cinco nombres en las explicaciones de cada color: spadix y fenicatus a propósito de badius, glaucus mal definido a partir de Servio como de ojos brillantes en lugar de 'tordo grisáceo', y calidus y petilus referidos a caballos con determinadas manchas. Sustituye el adjetivo de época imperial russeus derivado de russus 'rojo' por el clásico y poético roseus; a partir de la grafía etimológica myrteus corrige en mirteus la forma murteus propia del latín, de la que Pascual 2015, pp. 99-101 considera derivado el correspondiente término castellano morcillo con el sufijo de diminutivo a partir del color negro violáceo del fruto del arrayán (murta); en esa categoría incluye canus mencionado por Paladio en la siguiente; cambia candidissimus en candidus anticipándolo a albus; después de niger omite pressus, que solo menciona a propósito de mirteus; entre las capas variadas omite las formas raras abineus o albineus 'blanquecino', canus cum quouis colore 'cano con cualquier color', spumeus 'espumoso' y maculosus 'lleno de manchas'; llama cinereus 'gris ceniza' al murinus 'gris ratón', y omite obscurior 'más oscuro'.

La colección de hechos asombrosos de Solino (XXVII 27; XLV 6; XXVII 18) le proporciona noticias sobre el onagro (39) a partir de Plinio (Nat. VIII 108), sobre el comportamiento del caballo en la guerra y respecto a sus amos (43), y sobre el conocimiento del movimiento del caballo a partir de las orejas (47), de lo que también trata Plinio Nat. VIII 49; los comentarios al Antiguo Testamento de Jerónimo (Quaest. hebr. in gen. pp. 36.24 y 30.37-40), junto a una traducción latina del tratado ginecológico de Sorano, sobre la reproducción artificial en los équidos, ovejas y humanos, y sobre la influencia ejercida en el aspecto de las criaturas por las imágenes que ve la madre durante la concepción (57-58 y 60); el de Servio y sus adicionadores a las obras de Virgilio (Aen. XI 89; XII 82; Georg. III 82; Ecl. I 1), sobre el llanto de los caballos y su capacidad para predecir el futuro (43), la definición de los colores spadix o fenicatus (49), glaucus y giluus (50), albus y candidus (51), y mirteus (53), y la frase final sobre el jefe del rebaño (61), que no iba referida a musmo sino a tityrus; Vegecio (Mulom. III 7.1), sobre las razas de caballo más y menos longevas (44); Plinio (Nat. VIII 159, 157, 160, 162), algún dato sobre el ingenio de los caballos, sus virtudes en la batalla, su conciencia de la victoria y la derrota, la edad máxima de los caballos (43-44), y otros datos que le llegan a través de extractos; Festo a través de Pablo el Diácono (224.2; 372.25; 30.23), la definición de petilus (52),

${ }^{5}$ Cf. Moure 1990, pp. 264-266 y 1992, pp. 13-19 sobre lecturas de Paladio que podrían corregirse a partir de Isidoro, como ya indicó Pedro Chacón según Grial 1999, pp. 225-226. 
de ueredus (55) y de bigener (56); el comentario de Porfirión a Horacio (Carm. III 27.7), la definición de mannus y su equivalente en la lengua vulgar (55); el tratado de veterinaria de Quirón (795), el color calidus (52).

Otros datos remontan en parte y de forma indirecta a los agrónomos que menciona junto a Paladio en Orig. XVII 1.1: Varrón Rust. II 7.15 trató sobre los tipos de équidos y sus usos (56); Virgilio (Aen. IV 135; XI 660, 638) emplea sonipes, y menciona el cuello erguido ${ }^{6}$ y otras cualidades (Georg. III 83, 86, 88; VIII 80) de un buen caballo (45-46); Columela VI 27.1 trae una división tripartita de los caballos (56), explica los dos tipos de mulo y de asno (VI 37.2-4 y VII 1.1), y trata otras cuestiones que Isidoro conoce sobre todo a través de Paladio (61), como la rápida aceleración y frenado de los caballos (47), referida a los potros por el gaditano (VI 29.4). Algunos glosarios medievales recogen noticias, como las etimologías de asellus (38) y de caballus (42), que si no están tomadas de esta obra de Isidoro, podrían proceder de una fuente común hoy desconocida.

\section{Etimología Y SIGNIFICADO}

Isidoro (Orig. I 29) justifica que no es posible conocer la etimología de todas las palabras cuando son nombres arbitrarios o procedentes de lenguas desconocidas. Pero siempre que puede, más que su significado ofrece su supuesto origen mediante distintos procedimientos, de los que en este pasaje solo faltan las explicaciones ex contrariis, ex uocibus y ex origine ${ }^{7}$.

Explica a partir del latín las etimologías de asinus, caballus, badius, guaranis, dosina y ueredus, que en realidad proceden de otras lenguas, y tampoco acierta al atribuir un origen griego a mauro y mulus ${ }^{8}$. Al derivar caballus de cauus, badius de uado y equus de aequus o aequo se basa en cambios fonéticos que no experimentaron estos términos hasta época imperial o tardía. Por contra, suele ofrecer significados más fiables de las palabras cuyo origen no explica, como mannus, giluus, guttatus, candidus, albus, petilus, calidus, mirteus y burdo.

${ }^{6}$ En lugar de ardua (Georg. III 79) o adrectis (Aen. XI 496-497), erecta aparece en un pasaje de Vegecio (Mil. I 6.4), muy similar al de Paladio sobre los potros, entre las cualidades que debe mirar el militar que selecciona jóvenes soldados.

7 Cf. Codoñer 2002, pp. 47-77.

${ }^{8}$ Salvo mauro, Ernout y Meillet $1967^{4}$, pp. 51, 80, 64, 284, 184, 723 y 420 traen la etimología de estos y otros términos del pasaje, y señalan las creaciones de lexicógrafos sin existencia real en la lengua. 
Refiere los significados de glaucus, giluus, albus, mirteus y mannus mediante la cópula est o sunt, sobreentendida en el caso de guttatus y de candidus; y mediante los verbos appellantur o dicuntur seguidos de qui o quae en el caso de petili y calidi y de bigenera (mulus y burdo). Indica los sinónimos o glosas con los pronombres ipse e idem seguidos de et: badium ... ipse est et spadix; dosina ... idem et cinereus. Para las variantes vulgares emplea las construcciones uulgus uocat (eranem) y quem uulgo dicunt/uocant (guaranem y brunicum).

Expresa la causa con la preposición propter y sobre todo con las conjunciones quia y quod, si bien esta causa solo es tal en el caso de los compuestos bigenerum y sonipes, que no implican ni derivación ni barbarismo o forma corrupta (Orig. I 32); la causa está sobreentendida en guttatus y scutulatus a partir del sentido figurado de gutta como punctum y de scutum como orbis. Como si fueran compuestos explica la supuesta causa (quia, quod) de canum a partir de $\mathrm{CA}($ ndido $) \mathrm{N}($ igr $) \mathrm{VM}$, por constar el color cano de pelos blancos y negros, y de uarium a partir de V(iae imp)ARIVM colorum. Combina derivación y causa al unir la preposición a con quia, propter quod y quod: asellus a sedendo ... quia; caballus ... a cabo propter quod; mulus ... a Greco ... quod. Aunque solo conste la conjunción causal, la derivación también está presente en las explicaciones de equus, badius, eranis, dosina (junto a la glosa cinereus) y ueredus.

Con la preposición $a$ explica la derivación de spadix, junto a la glosa fenicatus (49), creyendo erróneamente que spadica es nominativo de la primera declinación en la antigua lengua griega de Sicilia, en lugar del acusativo en esa variante del dialecto dórico, como consta en el comentario a Virgilio (Georg. III 82) que figura entre los escritos de Probo, y en el texto de Gelio (II 26.8-10) que constituye la fuente de la explicación. Mediante el verbo interpretatur y las conjunciones explicativas quippe y enim ofrece la etimología griega y significado de onager de forma acertada, y de forma errónea de mauro y mulus, esta última transmitida en un pasaje corrupto que corrijo y explico en Pascual 2016b, pp. 30-32. En otro lugar (Orig. XII 6.28) atribuye correctamente al griego el término glaucus, que aquí quiso explicar de otro modo con la conjunción explicativa nam $^{9}$.

\footnotetext{
9 Para dar un sentido más completo a un texto sin revisar, algunas copias y editores añaden album o splendidum como predicativo de glaucum, y traen dixerunt en vez de dicunt. Cf. Pascual 2015, pp. 92-93.
} 
Explica correctamente Arcadicus a partir de la región griega, combinando origen y causa al jugar con el doble valor de derivación y lugar de donde del sintagma ab Arcadia. Recurre a las diferencias (Orig. I 31) en el caso de candidus $/$ albus $^{10}$, e implícitamente de petilus y calidus como dos tipos de color de caballo con manchas blancas, de mirteus frente a ceruinus como dos colores rojizos oscuros (púrpura y marrón), y en cierto modo de mirteus frente a fenicatus como dos colores púrpura (oscuro y claro). Presenta como supuestas formas corruptas asellus por aseddus, dosina por de asino, e implícitamente guaranem por eranem, y considera brunicus un neologismo (barbarolexis) del que procedería la forma buricus, que no menciona por creerla erróneamente más vulgar y tardía.

En otro pasaje (Orig. IX 1.6-7) contempla cuatro etapas en la historia del latín: la primitiva en que habrían sido compuestos los cantos de los salios; la latina durante el reinado de Latino y los reyes etruscos en que se redactaron las leyes de las XII tablas; la romana o clásica de los poetas Nevio y Virgilio y de los oradores Catón y Cicerón; y la mixta desde época imperial hasta su tiempo, que sufrió la corrupción formal y la irrupción de neologismos de otras lenguas. Pero en este pasaje no distingue las dos primeras etapas, pues su referente fundamental es el latín clásico, actualizado con términos de la cuarta etapa para adaptar el contenido a su época. A esta última etapa debía de atribuir las formas asociadas al sustantivo uulgus y al adverbio uulgo (guaranis/eranis y brunicus), y quizás dosina, mauro y burdo. En una de las dos primeras etapas tal vez situaba aseddus; pues aunque Lindsay y André editan asedus como origen de asellus a partir de los códices $X G Y K$, aseddus (38) tiene el apoyo de otros más fiables $(T U V W C D H)$ y de varios pasajes en que Isidoro explica de forma similar la etimología de subsellium y sella (Orig. XX 11.10 y 16.4). Parece entender uadius como el étimo de badius, y quizás ueredus como una forma arcaica frente a la clásica mannus y la tardía brunicus/buricus.

\section{ESQUEMA GENERAL DEL PASAJE Y CLASES DE ÉQUIDOS}

El propósito principal de la obra era transmitir el conocimiento heredado de interés general, finalidad práctica que cumplió mucho más allá de los límites cronológicos y geográficos del reino hispano-visigodo. En

${ }^{10}$ Cf. Codoñer 1992, pp. 39 y 248 (Differ. I 55). 
este pasaje ofrece de forma concisa la información disponible siguiendo un esquema que contempla dos especies y los cruces entre ambas. Para interpretar algunos términos resulta clarificador el paralelismo implícito entre la exposición sobre asnos y caballos. Con todo, debido a su prestigio e interés social, dedica mucha mayor atención a los caballos, sobre los que trata además de su edad, cualidades y principales razas nobles. Omite datos que considera superfluos, como los ejemplos de Alejandro Magno y de Julio César, citados por Solino (XLV 6, 9-10) y antes por Plinio (Nat. VIII 154-155) a propósito de caballos que no aceptaban a otro jinete a sus lomos, aludidos con el indefinido aliqui 'algunos' en lugar del sinónimo aliquot de Solino.

Al explicarlos, agrupa los colores con sus variantes de brillo y claridad en tres gamas según el predominio del tono rojizo o alazán, blanquecino o claro, y negruzco u oscuro, además de las capas de varios colores que sitúa entre la clara y la oscura. Por ello altera el orden de la lista inicial en este otro: 1, [2, 3] 7, 6, 12,10,11, 9, 8, 14, 5, 4, 15, 13, y también para tener en cuenta dos versos de Virgilio, y asociar a través de aeranis, dosina y $\mu \alpha \tilde{p} \rho \operatorname{ç}_{\text {los }}$ colores oscuros ceruinus, cinereus y niger con los neologismos guaranis, dosina y mauro, que designan el garañón, el caballo salvaje y el berberisco. Implícitamente, también el mannus o buricus 'poni' es asociado al color pressus o brunus 'pardo' a través de brunicus ${ }^{11}$.

Comienza tratando del asno y el caballo de forma conjunta, estableciendo su función común de cabalgadura, y su distinta índole o inteligencia, y clasificándolos según unos mismos criterios según los nombres de cada tipo de ellos, su condición de animal doméstico o salvaje, y su distinto tamaño y función, para terminar tratando de los resultados de la unión de asnos y caballos. Aunque solo menciona el caballo salvaje a propósito de un supuesto sinónimo del color cinereus (56), diferencia el asno y caballo domésticos (asinus y equus) del asno y caballo salvajes (onager y equiferus), y dentro del asno (40) y caballo (56) domésticos al más grande o noble (asinus Arcadicus y equus generosus) del vulgar de menor tamaño y destinado al trabajo (asellus y mannus). Por tanto, el contenido general viene a ser este:

I. AsNos: nombres, índole y clases según origen, tamaño y función (38-40).

${ }^{11}$ Cf. Pascual 2015, pp. 82-83. 
II. Caballos: nombres (41-42); índole (43) y clases según la edad (44), según las cualidades de hechura (45), de belleza (46), de conducta (47) y de colores (48-55); y según origen, tamaño y función (53-56).

III. Híbridos: de asno y yegua (mulo), de caballo y asna (burdégano), de onagro y asna, de otros géneros de animales (57-61).

Y este sería el esquema en latín de las dos principales especies de équidos y sus cruces:

\section{ASINI TARDI}

A. Nomina: asinus, asellus, Arcadicus (38-40)

B. Indoles: tarditas (38)

C. Genera:

a) Ferus: onager (39)

b) Mansueti:

1. Arcadicus: magnus (40)

2. Asellus: minor ad laborem (40)

\section{EQUI UIUACES}

A. Nomina: equus, caballus, sonipes (41-42)

B. Indoles: uinacitas (43)

C. Genera:
a) Ferus: equiferus (54)
b) Mansueti:
1. Generosi (44-53, 55-56, 59)
2. Vulgares: breuior et ad ue- hendum (55-56)

III. BigenerA

1) mulus ex equa et asino $(57,61)$

2) burdo ex equo et asina (61)

3) ex onagro et asina (57)

La estructura del pasaje, basada en asnos y caballos, determina que la tercera categoría de caballos (56) sea en realidad el resultado de cruzar asnos y caballos (mulo y burdégano), donde cabe incluir el híbrido de onagro y asna. El tecnicismo bigener, procedente de Varrón (Rust. II 8.1) y de Verrio Flaco a través de Festo, se refiere pues al cruce de caballo con asno, mientras que Columela (VI 27.1) aplicaba el adjetivo mularis a los caballos para engendrar mulos, con lo que la división tripartita del caballo queda en Isidoro en bipartita como en los asnos.

Así pues, a pesar de que el orden de la exposición esté en ocasiones alterado, y de la desigual extensión que dedica a asnos y a caballos, en ambos casos subyace una misma estructura. Ambos fueron empleados por el hombre 
como animales de silla y de tiro, aunque según las falsas etimologías propuestas fuera el asno el que tomara su nombre del verbo sedere 'sentarse' por haber sido domesticado antes que el caballo; y al sustituirlo este en esa función, tuvo que tomar su nombre equus de $\langle a\rangle$ equus porque se escogían equiparables en aspecto y velocidad para ser uncidos a las cuadrigas, explicación posterior a la generalización de la pronunciación monoptongada de /ae/ en época imperial. Después de distinguir el asinus Arcadicus del asellus, que era el de menor tamaño empleado comúnmente para trabajar (40), trata igualmente del equus empleado en las carreras frente al caballus, que había sido el término clásico para referirse a un caballo de trabajo, aunque él lo emplee como sinónimo de equus según el uso propio del latín tardío, mientras que buricus y ueredus designarían los caballos vulgares de trabajo y transporte. El sinónimo poético sonipes, empleado en el hexámetro desde Lucilio y Accio, no tiene correspondencia en el asno, pues si asellus aparece más en verso que en prosa desde época clásica ${ }^{12}$ hasta su tiempo, más que a razones métricas o estilísticas considero en Pascual 2016a que se debe a que los poemas suelen referirse al asno de trabajo y no al asno garañón.

La cualidad con que distingue al caballo del asno es la inteligencia, pues del asno destaca su torpeza y falta de raciocinio para resistirse al dominio del hombre (38), donde tardum alude al intelecto más que al paso ${ }^{13}$, que es muy ligero en los asnos salvajes (57). Entre otras razones, la escasa inteligencia del asno está justificada por el empleo figurado de asinus (Plaut., Pseud. 136; Cic., Pis. 73) y de asellus (Iuu. IX 92) referidos a una persona estúpida. Esa supuesta estupidez le permite además justificar que asellus derive de sedeo ${ }^{14}$, al ser la causa de que el hombre pudiera montar primero al asno, aunque el caballo acabara siendo el animal de silla por excelencia: priusquam equos caperent, homines huic presidere ceperunt, puntuación corroborada por Gloss. Ansil. AS 94: asinus ab assidendo dictus quia, priusquam usus equorum esset, his homines utebantur.

Del caballo resalta por contra su sagacidad (43), que en algunos aspectos considera similar e incluso superior a la del hombre. Frente al salmista (Vulg.

12 Verg., Georg. I 273; Prop. IV 1.21; Ou., Fast. I 399 etc. Catulo (97.10), Fedro (I 21, IV 1 etc.) y Persio (I 121) llaman asinus a la especie o al asno garañón.

${ }^{13}$ Virgilio (Georg. I 273) sí refiere la lentitud del burro de trabajo: tardi... agitator aselli.

${ }^{14}$ Con la coincidencia de sonidos juega Ovidio (Ars 543-544): senex pando Silenus asello / uix sedet. 
Psalm. 32.9) y otros autores que equiparaban los caballos con los asnos y con los mulos como carentes de intelecto, Isidoro lo presenta como el animal con cualidades más humanas, de acuerdo con la tradición de los autores grecorromanos y sus comentaristas prolongada en la sociedad visigoda. Ilustra esta condición casi humana con los centauros de la antigua Mitología como si fueran cruces de hombre y caballo, si bien en otro lugar explica que eran hombres a caballo (Orig. XI 3.37), como ya sostuvo entre otros Lucrecio (IV 739 y V 890-891). Sí acepta la noticia de Servio y Plinio sobre los caballos que lloran la muerte de sus amos, interpretando como real una ficción poética de Virgilio (Aen. XI 89-90) tomada de Homero (Il. XVII 426), sin más fundamento real que las lágrimas que los caballos derraman por causas físicas.

\section{V. ÉQUidOS SALVAJES: ONAGROS Y ECEBROS}

Siguiendo una doctrina común en la Antigüedad greco-latina, tanto en el asno como en el caballo distingue Isidoro la variedad doméstica de la salvaje, a la que llama respectivamente onager y equiferus (39 y 54), y le aplica los adjetivos ferus ${ }^{15}$ y agrestis $^{16}$. Trata del equiferus a propósito del color cinereus 'gris ceniza', que relaciona con el neologismo dosina al suponerlo derivado de de asino por ser un caballo con color 'de asno'. Equiferus es el étimo del castellano medieval ezebro o ecebro (luego encebro), y del término moderno zebra o cebra debido a su parecido y similar condición, por lo que el arcaísmo ecebro equivale al tecnicismo equiferus mejor que el sintagma caballo salvaje. De hecho, equiferus en el habla latina de época de Isidoro ya debía de presentar un sonido africado /č/ en lugar de la labiovelar, que primero había pasado a ser velar $/ \mathrm{k} /$ y luego palatalizada, y que más tarde adelantaría su realización en $/ \mathrm{t}^{\mathrm{t}} /$ antes de sonorizar en posición intervocálica en $/ \mathrm{d}^{\mathrm{z}} /$, escrita /z/ como en ezevro; la /i/ breve tónica tenía una realización abierta que se confundió con la /e/ en Época Imperial; la fricativa sorda intervocálica había

15 Asinus ferus como sinónimo de onager figura en Varrón (Rust. II 6.3 y II 1.5), Plinio (Nat. VIII 39, 72) y Amiano Marcelino (Rer. XXIII 4.7); asinus agrestis en Tácito (Hist. V 3.2), Amiano Marcelino (XXIV 8.5), el comentario de Servio ampliado (Verg., Georg. III 409), obras de Agustín (In psalm. 103, Serm. 3.41.2), y de otros autores (cf. MLW, s. u. asinus, 1031,40).

${ }^{16}$ En carta a Bonifacio de Maguncia, Gregorio III también llama agrestis al caballus salvaje (Epist. 28, ed. Jaffé, Bibl. rer. German., III 93). Cf. Mannhardt 1905, p. 151, MLW, s. u. agrestis (408.23) y equus (1343.52). 
sonorizado, según se colige entre otros indicios de la asociación etimológica entre Zephyrus y uere (Orig. XIII 11.8) ${ }^{17}$, y probablemente estaba ya extendida la síncopa entre la oclusiva y la vibrante. Varrón (Rust. II 1.5), Plinio (Nat. VIII 16.39) y Estrabón (III 4.15 y IV 6.10) mencionan equos feros o

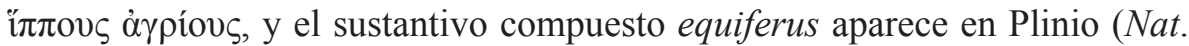
XXVIII 159, 197) entre los remedios médicos que estudio en Pascual 2012, pp. 127-134, referido a un animal distinto al caballo doméstico que ignoraron los médicos griegos.

Varios tipos de asno y caballo salvajes todavía fueron vistos en Roma a mediados del siglo III (Hist. August., Capitol. XX, Gord. 33.1, 3.7). La distribución del equiferus no coincide con la del onager, aunque desde tiempos de Isidoro se les suela confundir, como Espejo 1996, pp. 100-102. Siguiendo a Solino (27.27), Isidoro localiza el onagro en los desiertos de África; Plinio (Nat. VIII 16.39) los situaba además en Asia, y Varrón (Rust. II 1.5) en Frigia y Licaonia. El equiferus o ecebro, al que he dedicado un artículo en Pascual 2017, está documentado en una amplia franja de la Hispania Citerior que recorría el centro de la Península desde el páramo leonés hasta la estepa murciana, y en otras regiones de Europa Central y Oriental.

\section{VI. ÉQUIDOS DE RAZA NOBLE}

Frente a la escueta referencia al asno de raza para engendrar llamado arcádico (40), Isidoro (44) recoge la división de Vegecio (Mulom. 3.7.1) en caballos longevos y de vida más corta (norteafricanos e hispanos), a los que añade una tercera raza de la Galia. Las palabras frequens opinio est («es una opinión frecuente») debieron de ser transmitidas por error, pues en Vegecio formaban parte de la siguiente frase («que a los de los bárbaros no se debe dar la medicina de brebaje alguno»): Aetas longaeua Persis, Huniscis, Epirotis ac Siculis, breuior Hispanis ac Numidis. Frequens opinio est barbaricis nullarum potionum adhibendam medicinam. Cabría interpretar el texto de Isidoro refiriéndolas a los caballos de vida corta o mejor a todo el párrafo, pero no a la supuesta fama de los caballos galos como traduce André 1986, p. 68 («la réputation des chevaux gaulois est étendue»).

\footnotetext{
${ }^{17}$ Cf. Gil 1970, pp. 68-70 y 76-77 y 2004, pp. $153-155$ y $158-160$.
} 
Los antiguos galos tuvieron caballos aptos para la guerra, pero sobre todo caballos baratos para cargar, tanto al lomo como tirando de carros ${ }^{18}$. Si Isidoro podía incluir los caballos gálicos (Gallici) entre los caballos nobles, que en la Antigüedad no se destinaban a cargar (Sen., Dial. X 18.4), se debe a que consideraba propia de estos la función de cargar al lomo, frente a la raza vulgar que solo era apta para el tiro de carros pero no para la monta (56). Pues es la silla lo que caracteriza a la clase noble, sea como cabalgadura en los combates (preliis) o llevando cargas (oneribus), no para los honores (honoribus) como propone André 1986, p. 79 a partir de la lectura de solo tres códices $\left(C B Y^{1}\right)$, provocada por la grafía honeribus que empleaba Isidoro ${ }^{19}$, ya que en el diccionario que constituye el libro décimo, el orden alfabético impide suprimir la /h/ inicial (Orig. X 117).

Isidoro omite las noticias previas de Vegecio (Mulom. 3.6.1-4) sobre otros caballos nobles por ser de menor interés o utilidad: los de guerra de Turingia, Burgundia, Frigia, Sarmacia y Dalmacia; los de Armenia y Sofena para montar, y los capadocios para carreras de carro. Además de las dificultades para adquirir esos caballos, los escrúpulos religiosos le llevan a condenar esas antiguas carreras siguiendo a Tertuliano (Orig. XVIII 34.2, 36.1-2 y 41.3-4).

En cierto modo, las siete razas que menciona bastaban para abarcar las principales regiones productoras de caballos en su tiempo: el Nordeste de Europa (Vgnici), Asia (Persici), Grecia (Epirotae), Italia (Siculi), Hispania (Hispani), África (Numidae) y la Galia (Gallici). Además refiere una octava raza de caballo noble, pues el caballo mauro (55), como propuse en Pascual 2009, pp. 165-183, debe de corresponder a la raza berberisca del noroeste de África, más pequeña que la de los númidas. Isidoro trata de explicar mauro como si hubiera sido el nombre del caballo de color negro. Pero maurus nunca significó en latín 'negro' u 'oscuro', sino 'procedente o relativo a Mauretania', y el adjetivo para designar el caballo negro siempre fue niger,

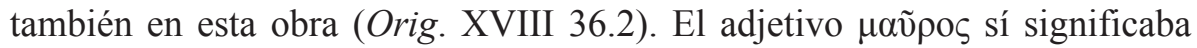
'negro' en la lengua griega común hablada en su época, a la que distingue en otro lugar (Orig. IX 1.4-5) de los cuatro dialectos griegos de la Antigüedad,

${ }^{18}$ Cf. Plaut., Aul. 495: ego faxim muli, pretio qui superant equos, sint uiliores Gallicis cantheriis («yo haría que los mulos, que superan en precio a los caballos, sean más baratos que los caballos de carga gálicos»); Pauly y Wissowa 1930, cols. 1.429-1.446, esp. col. 1433. Según Varrón (Rust. II 10.4) y César (Gall. IV 2.2), los galos son expertos sobre todo en jumentos.

${ }^{19}$ Cf. Lindsay 1911, p. xii; Gil 1973, p. 194 y Rodríguez-Pantoja 1974, p. 77. 
cuando llamaban al color negro $\mu \varepsilon ́ \lambda \alpha \varsigma$ (Orig. XIX 28.8). Aunque Corominas y Pascual 1987-1991, t. IV, p. 151 la acepten para el color del caballo, la etimología de mauro a partir del griego bizantino es tan infundada como la de Maurus a partir de la tez negra de los bereberes por el calor del verano, que vuelve a repetir (licet Mauri ob colorem a Graecis uocentur) a pesar de conocer otra teoría más próxima a la realidad procedente de Salustio (Jug. 17-18), según la cual Maurus sería una deformación de Medus en boca de los libios o africanos (Orig. IX 2.122; XIV 5.10). Estrabón (XVII 3.7) consideraba Maurus una palabra autóctona, referida a una tribu bereber dominante en otro tiempo y extinguida por las guerras; pero Mauri y Mavpov́бıь probablemente sean préstamos de la forma púnica Mahourim o Mauhaarim 'occidentales' ${ }^{20}$, con la que los cartagineses llamaban a los bereberes del noroeste de África. La definición Mauretania uocata a colore populorum (Orig. XIV 5.10) tal vez remonte a unos versos de Manilio (IV 729-730) basados en un juego de palabras entre el étnico latino Maurus y el adjetivo

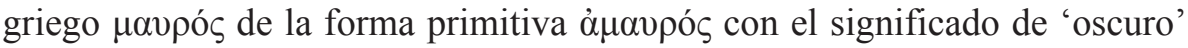
o 'poco visible': Mauretania nomen / oris habet titulumque suo fert ipsa colore. La etimología de Maurus a partir del griego bizantino también podría proceder de un escolio al sintagma concolor Indo / Maurus de Lucano (IV 678-679), donde el étnico latino aparece vinculado al color oscuro de la piel' ${ }^{21}$ a partir de ese mismo juego de palabras bilingüe propio de poetas, pues como señala Endt 1908, pp. 294-307, son numerosas las citas de Lucano en este libro y en el resto de las Etimologías que deben de proceder de escolios y comentarios.

\section{Sementales}

Isidoro no emplea admissarius 'garañón', referido al caballo y al asno semental por Varrón (Rust. II 7-8) y por Paladio (I 13-14) pero que había caído en desuso en el habla, ni trata esta función. Pero tanto guaranis en su época como asinus Arcadicus desde el siglo I designaban el asno y el caballo semental, aunque él asocie estos nombres a un color de caballo y a una clase de asno.

\footnotetext{
${ }^{20}$ Cf. Perin 1940, p. 232 y Pauly y Wissowa 1930, cols. 2.349-2.351.

${ }^{21}$ Juvenal (V 53 y XI 125) llama nigri a los Mauri y compara su piel con la más oscura del hindú (Mauro obscurior Indus).
} 
Explica el germanismo guaranis como derivado de la forma ficticia aeranis de aereus 'broncíneo' para asociarlo al color ceruinus 'cervuno' (53). Pero su significado debía de ser 'semental', que como indica Sofer 1975, p. 22, es el étimo del castellano garañón y de sus equivalentes en otras lenguas romances.

Justifica el nombre asinus Arcadicus en que los primeros asnos grandes y altos se exportaron desde Arcadia, pero teniendo en cuenta que se opone al pequeño asellus destinado al trabajo, cabe deducir que se refería sobre todo al garañón. El asinus Arcadicus ${ }^{22}$, que en tiempos de Varrón (Rust. II 1.14) era todavía el asno grande de Arcadia muy apreciado como garañón, pasó a designar el asno garañón de cualquier procedencia, como en un hexámetro de Eugenio de Toledo (Anth. I 387.3 Meyer): Mulus ab Arcadicis et equina matre creatus «Mulo engendrado de arcádicos y de madre equina».

\section{VIII. ÉQUidos VULGaRES Y PEQUEÑos PARA TRABAJAR EN EL CAMPO}

Mientras que el sintagma asellus Arcadicus figura en prosa y en verso en la obra de Columela o a él atribuida (VII 1 y X 344), Isidoro designa con asellus una categoría de asno vulgar más pequeño (asinus minor) empleado para trabajar en el campo, frente a la de mayor tamaño -empleada para montar y para engendrar- que denomina asinus Arcadicus. Esta división se basa en Columela (VI 37.3-4 y VII 1.1) y en Paladio (IV 14.3-4), quienes como explico en Pascual 2016a, oponen el pequeño asellus al asinus grande usado sobre todo como admissarius o garañón para criar mulos.

Como en los asnos, Isidoro distingue dos clases principales de caballos domésticos: una noble para la silla, identificable con las razas ligeras propias de zonas cálidas, y otra vulgar para el tiro, correspondiente a las razas pesadas de ponis y palafrenes de las zonas septentrionales de Europa. Con todo, los ponis también se usaron como cabalgadura, y una misma raza de caballo podía servir para cualquier función mediante la selección, el adiestramiento o la castración. El poni o raza de caballo más corto de estatura y longitud (equus breuior), llamado en latín clásico mannus ${ }^{23}$ y luego buricus -mal corregido aquí en brunicus - (55), es pues el equivalente de la clase de asno llamada asellus (40), hasta el punto de que en castellano el asellus 'borrico'

\footnotetext{
${ }^{22}$ Cf. Plaut., Asin. 333; Varr., Rust. II 1.14 y II 8.3; Colum. VII 1.1, X 344; Plin., Nat. VIII 167.

${ }^{23}$ Mart. XII 24.8 y Plin., Epist. IV 2.3 traen además la forma de diminutivo mannuli.
} 
terminó apropiándose del nombre de buricus, si bien burro aún designa el poni en el dialecto asturiano occidental según Corominas y Pascual 19871991, t. III, pp. 634-635.

En la lectura caballus antea cabo $(42)^{24}$, el adverbio temporal de los códices parece implicar que cabo fuera un sustantivo arcaico de la tercera declinación, fruto quizás de un cruce -más que de una sonorización tardíaentre los sustantivos capus y capo para el 'gallo castrado' y la antigua acepción de caballus como 'caballo castrado' (Mart. I 41.20). Pero en el pasaje de Isidoro no aparece la idea de castración ni es compatible con la causa que ofrece a continuación basada en la forma concaue ${ }^{25}$ (escrita por Isidoro concabet como en $T U V Y^{1}$ ), aunque sí aparece de forma explícita en algunas glosas $^{26}$; y aunque cabría interpretar cabo como un sustantivo derivado del verbo cauare escrito cabare, tal explicación no cuenta con el refrendo de texto alguno. Un poco más adelante hallamos una etimología basada en esa misma confusión de /u/ y /b/ en posición intervocálica (Orig. XII 8.4): Scabrones uocati a cabo, id est caballo, quod ex his creentur, donde cabo procede del ablativo del adjetivo cauus, interpretado como sinónimo de caballus a partir de la expresión virgiliana (Aen. II 260) cauo robore 'roble hueco' explicada en glosarios como equo ligneo ${ }^{27}$. Esta etimología aparece también en la lectura caballus antea a cabo de los códices $T$ y $B$, donde no creo que la preposición $a$ fuera añadida por los copistas ope ingenii, pues la frase carece de sentido («caballo se dijo antes de cavo»), ni que tomaran la expresión de esta explicación, pues en ese caso habrían suprimido el adverbio temporal. Más bien pienso que la preposición fue suprimida por otro $u$ otros copistas para dar algún sentido a la frase («caballo se dijo antes cavón»), y que la dificultad de interpretación procede de una mala lectura antea en lugar de autem. Vienen a corroborar mi hipótesis la frase caballus autem a cauo pede dictus en la edición de Clark 2006, p. 156, de un bestiario medieval basado en última instancia en un buen códice de Isidoro, así como la glosa caballus

${ }^{24}$ a cabo $T B^{1}$ : a cauo $B^{2}$ : cauo $U W C K$ : cabo $V X H Y$ Lind. And. : capo $D$.

${ }^{25}$ Grial 1599, pp. 223 y 225 la deriva de cauando a partir de Verg., Georg. III 87-88 (cauatque / tellurem), donde juega precisamente con el sonido /u/, pero no alude a caballus.

${ }^{26}$ Gloss. V 51.5: Cabonem equum castratum que nos caballum dicimus. Gloss. V 16.6: Cabonum equum castratum quem gaballum nos dicimus.

${ }_{27}$ GL, ed. Lindsay, III, 16 et 108 in Aen. II 260 (cod. Bern. 16, C, glossa 98). Cf. Cocco 1943, pp. 798-832; 1942, pp. 390-392. 
a cauo dictus ${ }^{28}$ («llamado caballo de cavo»). Cabe pues considerar la explicación de cabo como derivada de la de cauus a partir de una mala interpretación.

Isidoro ignora otros términos clásicos para referirse a un caballo vulgar de tiro, pues solo recoge el sentido figurado de canterium (Orig. XIX 19.15) ${ }^{29}$. En otro lugar (Orig. XX 16.5) menciona el caballus sagmarius, que alude a una de sus funciones propias como caballo de carga o albardón, de donde el italiano somaro, el catalán y aragonés somera, y el vasco zamari para este caballo grande y lento: sagma ... unde et caballus sagmarius, mula sagma$\mathrm{ria}^{30}$. Y emplea caballus como sinónimo de equus, lo que tal vez influyera en que al caballo noble le asigne también la función de cargar al lomo, que en la Antigüedad era propia del caballus y otros iumenta pero no del equus.

El hápax brunicus es un nomen fictum creado por algún gramático para explicar buricus a partir del adjetivo del latín visigodo brunus relativo a un color oscuro, ya aducido por Sofer 1975, pp. 67-68. Si en el habla tardía llegó a producirse esa metátesis favorecida por un cruce con brunus, los resultados romances, siempre derivados de buricus, corroboran que es este el término que Isidoro trata de explicar. La posición de brunicus a continuación de mauro explicado como 'negro' indica que Isidoro asocia la etimología de brunicus a otro color oscuro, más bien 'pardo' que 'castaño oscuro' como en su resultado en inglés brown o alemán braun, que como refiero en Pascual 2015, pp. 105-108, es una capa propia de los asturcones y de otros ponis.

Isidoro presenta ueredus como una forma perteneciente a un estadio cronológico más antiguo (ueredos antiqui dixerunt) que el caballo más pequeño mannus. Ambos podían ser caballos trotones (tollutarii) apropiados para montar durante un viaje (uectorii), función en la que destacaron los manni del norte de Hispania llamados Asturcones, cuya forma de correr fue adoptada por caballos de otros lugares y razas, como testimonia Vegecio a propósito del

28 Gloss. Paris, saec. IX. Cf. Hildebrand 1854, p. 39.

${ }^{29}$ El caballo castrado o cantherius, equivalente equino del gallo capus, era de paso más sosegado y por ello cómodo para viajar y tirar del carro, pero no para la guerra ni para las carreras. Lo mencionan entre otros Plauto, Lucilio, Catón, Cicerón y Columela, pero desde Vitruvio y Apuleyo hasta Ambrosio e Isidoro, el término se emplea más en sentido figurado.

${ }^{30}$ Cicerón (Top. 36) emplea además clitellarius con ese sentido de 'albardero'. También dorsuarius, aplicado al asellus (Varr., Rust. II 6.5) y al iumentum (Chir. 652), es el animal que carga a los lomos. 
caballo tottonarius y colatorius (Mulom. I 56.37 y III 6.7) ${ }^{31}$. Corresponde a uno de los cuatro tipos de caballo de Varrón (Rust. II 7.15), no válido para la guerra, para las carreras, ni para la cría de mulos, sino para el transporte como cabalgadura con silla además de tirando de un carro (uectorios... ad ephippium aut ad raedam $)^{32}$. Esta función uectoria del mannus o buricus y del ueredus se basaba en que tenían un paso más cómodo para el jinete y más seguro para el carro, debido tanto a sus patas más cortas como a su carácter menos fogoso, por ser de sangre fría. Sin embargo, desde época tardía la silla o cabalgadura, usada ahora también para llevar cargas al $10 \mathrm{mo}^{33}$, se consideró propia de la clase noble de caballos, mientras que la clase vulgar se destinaba al tiro. El adjetivo uulgare no alude a una calidad inferior como en Columela, sino a que lo empleaba el vulgo en el trabajo, frente a la función militar y el prestigio social del caballo noble propio de la clase social elevada.

El adjetivo breuiores designa el tamaño pequeño de los ponis, aunque en cierto modo cabría entenderlo referido en general a la proporción o forma más rechoncha de los caballos braquimorfos, incluyendo a los ueredi entendidos como caballos de tiro de acuerdo con la etimología propuesta, y referidos a esos caballos robustos propios sobre todo del centro y norte de Euro$\mathrm{pa}^{34}$. Pues tanto en el pasaje como en la realidad, el poni y el caballo de tiro constituyen dos variedades de distinto tamaño de un mismo tipo de caballo de parecidas proporciones y origen común, oriundas del norte de Europa, y muy aptas para el tiro y en general para el trabajo, frente al caballo ligero de zonas más cálidas. Y aunque cada término tenía su propio significado y etimología, manni y ueredi pertenecían al género de caballos que Isidoro llama vulgar y gregario para el transporte (uulgare atque gregarium ad uehendum). Ofrece dos supuestas etimologías de ueredus basadas en que originariamente

${ }^{31}$ Cf. Ortoleva 2001, pp. 126-142 y 151-158; Pascual 2008, pp. 132-155.

${ }^{32}$ De las cuatro funciones principales en que Varrón (Rust. II 7.15) dividía los caballos: la batalla, el transporte, la cría y la carrera, Columela omite la primera, pues los caballos para combatir eran criados entonces por el Estado más que por los particulares a quienes dirigía su obra, mientras que Isidoro sí trae esta función como la más propia de la primera clase de caballos.

${ }^{33}$ Vegecio (Mulom. III 6.2) considera que los caballos nobles estaban destinados a los combates, al circo y a la silla (proeliis, circo, sellis); y también Isidoro, junto a la guerra y la carga, considera implícitamente la silla como la tercera función propia de los buenos caballos, pues la excluye explícitamente como propia de los caballos vulgares (56).

${ }^{34}$ Como es sabido, el compuesto paraueredus es el étimo del término para 'caballo' en alemán (Pferd). 
habría servido para llevar o tirar (ueho) de los carros (reda), o porque iba por los mismos caminos por los que iban los carros. El sintagma uias publicas que refiere al ueredus lo hallamos referido al mannus o buricus en un texto de San Jerónimo (In eccles. X 5-7 = PL XXIII 1093B) que podría ser una de las fuentes del pasaje: dignitate perflati uias publicas mannis terant $t^{35}$.

Marcial (XII 14.1 y XIV 86.1) mencionaba el ueredus como un caballo rápido para ir a cazar y con silla de montar, pero más tarde fue sobre todo el nombre del caballo de posta, empleado en el correo oficial del Imperio; el pequeño mannus fue más usado en viajes cortos (Hor., Carm. III 27.7), pues corría sin sacudir la espalda, tanto cabalgando como tirando de un carro, especialmente por personas ricas (Lucr. III 1063; Hor., Epod. 4.14; Epist. I 7.77; Sen., Epist. 87.10) y por mujeres (Prop. IV 8.15; Ov., Am. II 16.49). En el siglo IV, Ausonio (Epist. 2.7) asociaba mannus y ueredus como dos tipos de caballo apropiados para viajar: uel celerem mannum uel ruptum terga ueraedum («o un poni veloz o un palafrén de espalda rota»). Pero Isidoro va más allá al agruparlos dentro de la misma clase de caballo.

IX. ÉQUidOS CRUZADOS E HíBRIDOS:

MULOS, BURDÉGANOS Y CRÍAS DE ONAGRO Y ASNA

Isidoro emplea bigener para referirse al animal nacido de dos especies distintas, y reserva hybrida para el cruce de jabalí con cerda, que en latín valía para el cruce entre la variedad salvaje y la doméstica de cualquier especie (Plin., Nat. VIII 213), cruce que también era designado con el término latino semiferus. Utiliza el término mulus con la acepción técnica de 'animal nacido de asno y yegua', mientras que para el 'animal nacido de caballo y asna' utiliza el neologismo de época imperial burdo (61), equivalente de los términos hinnus o hinnulus de Varrón (Rust. II 8.1-8; Ling. IX 28) y Columela (VI 37.5), que ya en el siglo I d. C. considera anticuados Plinio (Nat. VIII 172) ${ }^{36}$. Isidoro solo refiere uno de los ocho cruces teóricamente posibles de ecebros y onagros con caballos y asnos, el de onagro y asna, que podría considerarse hybrida o semiferus aunque sea el resultado de cruzar dos especies distintas; a partir de un controvertido pasaje de San Jerónimo añade que da un asno veloz (asinus uelox ex onagro et asina). Puesto que las razas híbridas

${ }^{35}$ Usa una expresión de Horacio (Epod. 4.14): [uiam] Appiam mannis terit.

${ }^{36}$ Adams 1993, pp. 35-61, señala otros usos de estos términos. 
y mezcladas se deben a la intervención del hombre, recoge además el efecto en el feto de mostrar imágenes de ejemplares hermosos a yeguas y a otras hembras (ovejas, palomas y mujeres) en el momento de concebir, y refiere otros cruces entre distintas especies de animales: jabalíes con cerdos, oveja con cabrón, y cabra con carnero ${ }^{37}$.

\section{Conclusiones}

Parte de la estructura del pasaje está oculta por una metodología basada en la recopilación de citas, que son ordenadas atendiendo a la etimología real o supuesta de determinados nombres más que a su significado y a la exposición ordenada del contenido. Pero algunas cuestiones pueden resolverse teniendo en cuenta que Isidoro partió de un mismo esquema para el asno y el caballo, propio de un tratado naturalista sobre animales. Pero mientras que explica onager ('asno salvaje') frente a asinus ('asno doméstico'), y asinus Arcadicus (que designaba el 'asno garañón' aunque solo trate su etimología) frente a asellus ('burro vulgar'), en el caso del caballo trata del caballo garañón (guaranis), del salvaje (equiferus) y del vulgar (mannus y ueredus) en relación a nombres de colores, al igual que en el caso del caballo mauro ('berberisco'). Ese mismo interés lingüístico justifica las formas ficticias aseddus, (a)eranis y brunicus. Al explicar los nombres de colores, los ordena en rojizos, claros, variados y oscuros a partir de una fuente desconocida, alterando el orden de la lista previa tomada de Paladio. El empleo de caballus como sinónimo de equus permite entender que explique caballus a partir del adjetivo cauns referido a equus por Virgilio, y que generalice al equus la función de llevar cargas (honeribus) propia del caballus.

Buena parte del pasaje acumula textos no siempre acertados de escritores y gramáticos, pero en conjunto constituye una valiosa síntesis y actualización terminológica y científica. Isidoro organiza noticias de épocas diversas, de autores paganos y cristianos, y de obras tan distintas como los poemas virgilianos con sus comentarios y la literatura técnica y científica; incorpora neologismos y explicaciones a partir de fuentes no siempre conocidas; omite los términos y contenidos menos claros o de menor interés, y ocasionalmente altera la forma y el significado etimológico o en la lengua que ofrecían las fuentes. Algunos lemas $(38,41-42,52-56,59)$ contienen indicios de que pudo

\footnotetext{
${ }^{37}$ Cf. Pascual 2016b, pp. 29-45.
} 
servirse de obras y extractos perdidos con datos no documentados antes ${ }^{38}, \mathrm{y}$ en los que ya habrían sido sustituidos términos desusados, como hinnus por burdo, y eliminados otros.

En mi exposición y en la edición del pasaje en apéndice propongo correcciones respecto a la edición de André, tales como aseddus en lugar de asedus (38), autem a por antea (42), ideo por idem de acuerdo con el sentido (53), honeribus por honoribus (56), Hana por Ana y $\mu$ $\lambda_{0} \varsigma \varsigma$ por uel que traspongo con las tres palabras previas a la oración causal que sigue (57), coitum por coitu conforme a la sintaxis latina (58), y lecturas de otros códices, como maximi ... clunes por maxime clunis siguiendo a Paladio (45), dicunt por dixerunt (50) y dosina por dosinus (54), y sigo otros criterios gráficos y de puntuación $^{39}$. Tampoco considero necesario interpolar splendidum (50), color (55) y dicitur donde se puede sobreentender est 'existe' (57), ni corregir eorum en earum (60), que puede referirse a uultus o quales o a un neutro genérico ('esas cosas'). Tanto estos criterios de edición como el tipo de análisis de este artículo podrían aplicarse con resultados parecidos a otros pasajes del libro XII, sobre todo del capítulo primero sobre el ganado.

\section{BiBLIOGRAFÍA}

Adams, J. N. 1993: «The generic use of mula and the status and employment of female mules in the Roman World», RhM 136, pp. 35-61.

André, J. 1986: Isidore de Séville, Étymologies, livre XII. Des animaux. Texte établi, traduit et commenté, París.

Arévalo, F. 1801: S. Isidori Hispalensis Episcopi, Hispaniarum doctoris, Opera omnia, Roma.

Clark, W. B. 2006: A Medieval Book of Beasts: The Second-Family Bestiary: Commentary, Art, Text and Translation, Nueva York.

Cocco, V. 1942: «Lat. cantherius, 'cavallo castrato' e la nuova base mediterranea kanth- 'curva, rotondità'», Studi Etruschi 16, pp. 390-392.

${ }^{38}$ Cf. Fontaine $1983^{2}$, t. II, pp. $730-749$ y $811-812$.

39 Siguiendo las grafías de $T$ y otros códices, y explicaciones de otros pasajes de la obra, escribo /e/ en lugar de los diptongos /ae/ (salvo Aetas como T) y /oe/, quum para la conjunción (I 27.4); suboles (IX. 5.13); Vgnicis (IX 2.66); mejor que cenoceualos como T (XX 9.9), cenocefalos como otros códices (XII 2.32, 7.70), ostes (XV 7.4), aderente, irco, hii, abtum, tipis, hibride, titirus. Cf. Lindsay 1911, p. xii y Gil 1970, pp. 55-57 y 68-69. 
Cocco, V. 1943: «Caballus: Studio lessicografico ed etimologico», Atti della Reale Accademia d'Italia. Memorie della Classe di scienze morali e storiche, 7.3, pp. 798-832.

Codoñer Merino, C. 1992: Diferencias. Libro I; introducción, edición crítica, traducción y notas, París.

Codoñer Merino, C. 2002: «La 'etimología' en Isidoro», en Introducción al libro X de las «Etymologiae»: su lugar dentro de esta obra. Su valor como diccionario, Logroño, pp. 47-77.

Corominas, J. y Pascual, J. A. 1987-1991: Diccionario crítico etimológico castellano e hispánico, Madrid, 6 vols.

Díaz y Díaz, M. C. 1982: «Introducción general» a San Isidoro de Sevilla: Etimologías, Edición bilingüe de J. Oroz Reta y M. A. Marcos Casquero, Madrid, vol. I, pp. 1-257.

Endt, J. 1908: «Isidorus und die Lucanscholien», Wiener Studien 30, pp. 294-307.

Ernout A. y Meillet, A. 1967²: Dictionnaire étymologique de la langue latine: Histoire des mots, París.

Espejo, M. M. 1996: Los nombres de color en la naturaleza, Granada.

Fontaine, F. 1983²: Isidore de Seville et la culture classique dans l'Espagne wisigothique, París.

Fontaine, F. 2000: «Compilator», en Isidore de Seville: genèse et originalitè de la culture hispanique au temps des Wisigoths, Turnhout, pp. 329-344.

Gil, J. 1973: «Para la edición de textos visigodos y mozárabes», Habis 4, pp. 189-234.

Gil, J. 2004: «El latín tardío y medieval (siglos VI-XIII)», en Cano, R. (ed.), Historia de la lengua española, Barcelona, pp. 149-184.

Grial, J. 1599: Diui Isidori Hispal. Episcopi Opera Philippi II Cathol. Regis iussu e vetustis exemplaribus emendata, Madrid.

Hildebrand, G. F. 1854: Glossarium Latinum Bibliothecae Parisinae Antiquissimum saec. IX, descripsit, primum edidit, adnotationibus illustravit, Gotinga.

Lindsay, W. M. 1911: Isidori Hispalensis episcopi etymologiarum sive originum libri XX. Recognovit brevique adnotatione critica instruxit..., Oxford.

Mannhardt, W. 1905: Wald und Feldkulte, Berlín.

Martín, J. C. 2002: La «Renotatio librorum Domini Isidori» de Braulio de Zaragoza (†651). Introducción, edición crítica y traducción, Logroño.

MLW: Mittellateinisches Wörterbuch bis zum ausgehenden 13. Jahrhundert, Múnich, 1967-

Moure Casas, A. M. 1990: Rutilio Tauro Emiliano Paladio: Tratado de agricultura. Introducción, traducción y notas, Madrid.

Moure Casas, A. M. 1992: «S. Isidoro de Sevilla: el valor de la tradición indirecta de Paladio», $C F C(L)$ 3, pp. 9-22. 
Ortoleva, V. 2001: «La terminologia greco-latina per designare le andature del cavallo (con un'appendice sull'etimologia dell'italiano danzare)», IF 106, pp. 126-163.

Pascual Barea, J. 2008: «Razas y empleos de los caballos de Hispania según los textos griegos y latinos de la Antigüedad», en Santamaría Hernández, M. T. (ed.), La Transmisión de la Ciencia desde la Antigüedad al Renacimiento, Cuenca, pp. 117-202.

Pascual Barea, J. 2009: «Un nuevo sustantivo latino en Isidoro de Sevilla (Orig. XII 1.55), mauro, mauronis, 'caballo moro' étimo del español medieval morón», en Conde Parrado, P. P. y Velázquez, I. (eds.), La Filología Latina: mil años más, Burgos, vol. 1, pp. 165-183.

Pascual Barea, J. 2012: «Las propiedades terapéuticas del equiferus desde Plinio hasta el siglo XVI», en Santamaría Hernández, M. T. (ed.), Textos médicos grecolatinos antiguos y medievales: Estudios sobre composición y fuentes, Cuenca, pp. 125-150.

Pascual Barea, J. 2015: «Los veinte nombres de colores de caballos en Isidoro de Sevilla (orig. 12,1,48-55)», en Ferragut Domínguez, C. y Santamaría Hernández, M. T. (eds.), Via ad sapientiam: latín, griego y transmisión del conocimiento, SPhV 17, Valencia, pp. 81-110.

Pascual Barea, J. 2016a: «Asinus y asellus: los dos tipos de asno doméstico en latín clásico», Pallas 101, pp. 279-291.

Pascual Barea, J. 2016b: «Notas al pasaje de Isidoro sobre el mulo y otros híbridos y sobre transmisión al feto de imágenes vistas por la madre», en Santamaría Hernández, M. T. (ed.), Traducción y transmisión doctrinal de la Medicina grecolatina desde la Antigüedad hasta el Mundo moderno: nuevas aportaciones sobre autores y textos, Cuenca, pp. 25-52.

Pascual Barea, J. 2017: «Equiferus hispanus o cebro ibérico: el caballo salvaje de la Península Ibérica desde la Antigüedad a Época Moderna», en Doyen, A. M. y Van den Abeele, B. (eds.), Actes du Colloque «Chevaux, chiens, faucons», Louvain-la-Neuve, 24-26 mars 2011, Lovaina-la-Nueva.

Pauly, A. y Wissowa, G. 1930: Realencyclopädie der classischen Altertumswissenschaft, Stuttgart, reed., vol. 28.

Perin, I. 1940²: «Onomasticon», en Forcellini, E., Lexicon totius Latinitatis, Padua, vols. 5-6.

Rodríguez-Pantoja, M. 1974: «Notas de ortografía isidoriana», Habis 5, pp. 65-91.

Sofer, J. 1975²: Lateinisches und Romanisches aus den Etymologiae des Isidorus von Sevilla: Untersuchungen zur Lateinischen und romanischen Wortkunde, Hildesheim (Gotinga, 19301).

Velázquez Soriano, I. 2003: Latine dicitur, vulgo vocant. Aspectos de la lengua escrita y hablada en las obras gramaticales de Isidoro de Sevilla, Logroño. 


\section{ApÉNDICE: TeXTo REVISADO}

38. Asinus et asellus a sedendo dictus quasi aseddus; sed hoc nomen, quod magis equis conueniebat, ideo hoc animal sumpsit quia, priusquam equos caperent, homines huic presidere ceperunt. Animal quippe tardum et nulla ratione renitens, statim ut uoluit sibi homo substrauit. 39. Onager interpretatur asinus ferus. On quippe Greci asinum uocant, agrion ferum. Hos Africa habet magnos et indomitos et in deserto uagantes. Singuli autem feminarum gregibus presunt. Nascentibus masculis zelant et testiculos eorum morsibus detruncant, quod cauentes matres eos in secretis locis occultant, etc. 40. Asinos Arcadicos dictos eo quod ab Arcadia primum uecti sunt magni et alti. Minor autem asellus agro plus necessarius est, quia et laborem tolerat et neglegentiam propemodum non recusat. 41. Equi dicti eo quod, quando quadrigis iungebantur, equabantur, paresque forma et similes cursu copulabantur. 42. Caballus autem a cabo dictus, propter quod gradiens ungula inpressa terram concabet, quod reliqua animalia non habent. Inde et sonipes, quod pedibus sonat. 43. Viuacitas equorum multa: exultant enim in campis, odorantur bellum, excitantur sono tube ad prelium, uoce accensi ad cursum prouocantur, dolent quum uicti fuerint, exultant quum uicerint. Quidam ostes in bello sentiunt, adeo ut aduersarios morsu petant; aliqui etiam proprios dominos recognoscunt, obliti mansuetudinis si mutentur; aliqui preter dominum dorso nullum recipiunt. Interfectis uel morientibus dominis multi lacrimas fundunt. Solum enim equum propter hominem lacrimare et doloris affectum sentire. Vnde et in centauris equorum et hominum natura permixta est. Solent etiam ex equorum uel mestitia uel alacritate euentum futurum dimicaturi colligere. 44. Aetas longeua equis Persicis, Vgnicis, Epirotis ac Siculis in annis ultra quinquaginta; breuior autem Spanis ac Numidis, et Gallicis, frequens opinio est. 45. In generosis equis, ut aiunt ueteres, quattuor expectantur: forma, pulcritudo, meritum atque color. Forma, ut sit ualidum corpus et solidum, robori conueniens altitudo, latus longum, substrictus, maximi et rotundi clunes, pectus late patens, corpus omne musculorum densitate nodosum, pes siccus et cornu concabo solidatus. 46. Pulcritudo, ut sit exiguum caput et siccum, pelle prope ossibus aderente, aures breues et argute, oculi magni, nares patule, erecta ceruix, coma densa et cauda, ungularum soliditatis fixa rotunditas. 47. Meritum, ut sit animo audax, pedibus alacer, trementibus membris, quod est fortitudinis indicium; quique ex summa quiete facile concitetur, uel ex citata festinatione non difficile teneatur. Motus autem equi in auribus intellegitur, uirtus in membris trementibus. 48. Color hic precipue expectandus: badius, aureus, roseus, mirteus, ceruinus, giluus, glaucus, scutulatus, canus, candidus, albus, guttatus, niger; sequenti autem ordine, uarius ex nigro badioque distinctus; reliquus uarius color uel cinereus, deterrimus. 49. Badium autem antiqui uadium dicebant, quod inter cetera animalia fortius uadat. Ipse est et spadix, quem fenicatum uocant, et dictus spadix a colore palme, quam Siculi spadicam uocant. 50. Glaucus uero est ueluti pictos oculos habens et quodam splendore perfusos. Nam glaucum ueteres dicunt. Giluus autem melinus color est subalbidus; 
guttatus, albus nigris interuenientibus punctis. 51. Candidus autem et albus inuicem sibi differunt. Nam albus cum quodam pallore est, candidus uero niueus et pura luce perfusus. Canus dictus, quia ex candido colore et nigro est. Scutulatus uocatus propter orbes, quos habet candidos inter purpuras. 52. Varius, quod uias habeat colorum inparium. Qui autem albos tantum pedes habent, petili appellantur; qui frontem albam, calidi. 53. Ceruinus est quem uulgo guaranem dicunt; eranem ideo uulgus uocat, quod in modum erei sit coloris. Mirteus autem est pressus in purpura. 54. Dosina autem dictus, quod sit color eius de asino, idem et cinereus. Sunt autem hii de agresti genere orti, quos equiferos dicimus, et proinde ad urbanam dignitatem transire non possunt. 55. Mauro niger est; nigrum enim Greci mauron uocant. Mannus uero equus breuior est, quem uulgo brunicum uocant. Veredos antiqui dixerunt quod ueherent redas, id est ducerent; uel quod uias publicas currant, per quas et redas ire solitum erat. 56. Equorum tria sunt genera: unum generosum, preliis et honeribus abtum; alterum uulgare atque gregarium ad uehendum, non ad equitandum abtum; tertium ex permixtione diuersi generis ortum, quod etiam dicitur bigenerum quia ex diuersis nascitur, ut mulus. 57. Mulus autem a Greco tractum uocabulum habet, quod iugo pistorum subactus tardas molendo ducat in girum molas. Grece enim hoc $\mu$ v́ $о$ s. Iudei asserunt quod Hana abnepos Esau equarum greges ab asinis in deserto ipse fecerit primus ascendi, ut mulorum inde noua contra naturam animalia nascerentur. Onagros quoque ab hoc admissos esse ad asinas: et ipsum istiusmodi repperisse concubitum, ut uelocissimi ex his asini nascerentur. 58. Industria quippe humana diuersum animal in coitum coegit, sicque adulterina commixtione genus aliud repperit. Sicut et Iacob contra naturam colorum similitudines procurauit. Nam tales fetus oues illius concipiebant, quales umbras arietum desuper ascendentium in aquarum speculo contemplabantur. 59. Denique et hoc ipsud in equarum gregibus fieri fertur, ut generosos obiciant equos uisibus concipientium, quo eorum similes concipere et creare possint. Nam et columbarum dilectores depictas ponunt pulcerrimas columbas isdem locis, quibus ille uersantur, quo rapiente uisu similes generent. 60 . Inde est quod quidam grauidas mulieres iubent nullos intueri turpissimos animalium uultus, ut cenocefalos et simios, ne uisibus occurrentes similes fetus pariant. Hanc enim feminarum esse naturam ut quales perspexerint siue mente conceperint in extremo uoluptatis estu, dum concipiunt, talem et subolem procreent. Etenim anima in usu uenerio formas extrinsecus intus transmittit, eorumque satiata tipis rapit species eorum in propriam qualitatem. 61. In animantibus bigenera dicuntur que ex diuersis nascuntur, ut mulus ex equa et asino, burdo ex equo et asina, hibride ex apris et porcis, titirus ex oue et irco, musmo ex capra et ariete: est autem dux gregis.

Fecha de recepción de la primera versión del artículo: 28/09/2015

Fecha de aceptación: 12/01/2016

Fecha de recepción de la version definitiva: 20/01/2016 